\title{
Escala de Eficácia Docente para Práticas Inclusivas: Validação da TeaCher EFFicacy for InCLUSIVE Practices (TEIP) SCALE ${ }^{1}$ TEACHER EFFICACY FOR INCLUSIVE PRACTICES (TEIP) SCALE VALIDATION
}

\author{
Bárbara Amaral MARTINS² \\ Miguel Claudio Moriel CHACON ${ }^{3}$
}

\begin{abstract}
RESUMO: O objetivo desta pesquisa foi analisar as propriedades psicométricas da versão brasileira da Teacher Efficacy for Inclusive Practices (TEIP) Scale. A versáo traduzida e adaptada à cultura brasileira denomina-se Escala de Eficácia Docente para Práticas Inclusivas (EEDPI) e foi aplicada a uma amostra de 308 professores de Educaçáo Infantil e Ensino Fundamental I e II, no interior do estado de Mato Grosso do Sul. A Análise Fatorial Exploratória evidenciou que suas propriedades psicométricas são adequadas, bem como a existência de dois fatores, nomeados "Regência em sala de aula" e "Planejamento e colaboração". A mesma amostra também respondeu à Escala de autoeficácia de professores: versão breve, considerada "padrão-ouro", a fim de avaliarmos o grau de eficácia da EEDPI em medir o que se propõe, a partir da relação com um critério externo. A Análise de Correlação de Spearman revelou a existência de uma correlação positiva entre as subescalas dos instrumentos, oscilando entre moderada e forte. A EEDPI ainda apresenta boa consistência interna (coeficientes de Alfa de Cronbach 0,89, 0,88 e 0,92) e mostra-se um instrumento que pode auxiliar na avaliação e no acompanhamento da autoeficácia docente diante da inclusão e na proposição das intervençóes oportunas.
\end{abstract}

PALAVRAS-CHAVE: Educação Especial. Educação inclusiva. Eficácia. Instrumentos de mensuração.

\begin{abstract}
The purpose of this research was to analyze the psychometric properties of the Brazilian version of Teacher Efficacy for Inclusive Practices (TEIP) Scale. The version translated and adapted to Brazilian culture is called Escala de Eficácia Docente para Práticas Inclusivas (EEDPI) and was applied to a sample of 308 teachers of Early Childhood Education and Elementary Education I and II, in the state of Mato Grosso do Sul. The Factorial Exploratory Analysis showed that its psychometric properties are adequate, as well as the existence of two factors, named "Classroom management" and "Planning and collaboration". The same sample also responded to the Teacher self-efficacy Scale: short version, considered "gold standard", in order to evaluate the efficacy of the EEDPI in measuring what it proposes, based on the relation with an external criterion. Spearman's Correlation Analysis revealed the existence of a positive correlation between the subscales of the instruments, ranging from moderate to strong. The EEDPI still presents good internal consistency (Cronbach's alpha coefficients $0.89,0.88$ and 0.92 ) and it is an instrument that can aid in the evaluation and monitoring of teacher self-efficacy in view of the inclusion and proposition of the appropriate interventions.
\end{abstract}

KEYWORDS: Special Education. Inclusive education. Efficacy. Measuring instruments.

\section{INTRODUÇÁo}

A autoeficácia corresponde às crenças que o indivíduo possui a respeito de suas capacidades, com a finalidade de organizar e executar as açóes necessárias para a produçáo de determinadas realizaçóes (Bandura, 1997). Nesse sentido, a motivaçáo, o estado afetivo e as açôes humanas dependem mais daquilo que a pessoa acredita ser real do que o que verdadeiramente é, de modo que as suas percepçóes alteram o julgamento e o uso do conhecimento e das habilidades que apresenta (Bandura, 1997; Pajares \& Olaz, 2008).

\footnotetext{
${ }^{1}$ http://dx.doi.org/10.1590/s1413-65382620000100001

${ }^{2}$ Doutora em Educação pela Universidade Estadual Paulista Júlio de Mesquita Filho (UNESP), Campus de Marília. Professora Adjunta da Universidade Federal do Mato Grosso do Sul, Campus do Pantanal, Brasil. Bolsista da Coordenação de Aperfeiçoamento de Pessoal de Nível Superior (CAPES). Programa de Doutorado Sanduíche no Exterior (Universidade do Minho, Portugal) - Processo no 88881.132728/2016-01. Corumbá/Mato Grosso do Sul/Brasil. Email: barbara.martins@ufms.br. ORCID: https:// orcid.org/0000-0003-4278-1661

${ }^{3}$ Doutor em Educação pela Universidade Estadual Paulista - UNESP, Campus de Marília. Professor Assistente Doutor do Departamento de Educação Especial da UNESP, Campus de Marília. Marília/São Paulo/Brasil. Email: miguelchacon@marilia.unesp.br. ORCID: https://orcid.org/0000-0002-6473-8958
} 
Isso significa que as expectativas que o indivíduo possui a respeito de sua eficácia pessoal determinam se um dado comportamento será iniciado, o nível de esforço que será despendido, por quanto tempo enfrentará os obstáculos e as experiências aversivas, a quantidade de estresse que experimentará, ao lidar com as exigências ambientais, e, até mesmo, sua vulnerabilidade à depressão (Bandura, 1978, 2008). Fortes crenças de autoeficácia permitem a manutenção de um estado sereno, diante de atividades difíceis, enquanto crenças enfraquecidas tendem a ocasionar a percepção de que a tarefa oferece um nível de complexidade irreal, gerando ansiedade e estresse (Pajares \& Olaz, 2008).

A autoeficácia atua sobre os processos cognitivos, motivacionais, afetivos e seletivos (Andreu, Pallarés, \& Juárez, 2004; Bandura, 1997; Navarro, 2007). Estes serão apresentados separadamente apenas por fins didáticos, pois regulam o funcionamento humano de maneira integrada. No aspecto cognitivo, a autoeficácia influenciará a positividade ou a negatividade dos pensamentos que antecedem as açóes, conduzindo o estabelecimento de objetivos e o compromisso com eles, de modo a favorecer ou inibir uma dada conduta. Assim, crenças elevadas estão relacionadas a metas ambiciosas e grande dedicação para alcançá-las (Andreu, Pallarés, \& Juárez, 2004; Bandura, 1997; Navarro, 2007). Similarmente, não se estabelecem metas consideradas inatingíveis (Martínez, 2004); por isso, ressalta-se o papel da cognição na aquisição e na regulação do comportamento, destacando-se que experiências passageiras podem ocasionar efeitos duradouros, na medida em que são codificadas e retidas na memória (Bandura, 1978). Ao sugestionar a disposição do pensamento, as crenças de eficácia afetam a compreensão do indivíduo a respeito de suas circunstâncias existenciais, visto que, ao possuir uma autoeficácia elevada, o foco de sua atenção recai sobre as atuais oportunidades de vida (Bandura, 2004, 2008). Segundo o autor:

Mesmo em ambientes com oportunidades limitadas e muitas restriçóes, eles acreditam que, por meio de engenhosidade e perseverança, as probabilidades podem ser superadas. Aqueles acossados com dúvidas sobre si próprios se debruçam sobre os impedimentos e facilmente se convencem da futilidade de seus esforços. Eles alcançam sucesso limitado, mesmo em ambientes que oferecem muitas oportunidades. (Bandura, 2004, p. 37, tradução nossa).

Considerando-se que a motivação tende a resultar da cognição, consequentemente será afetada pela antecipaçáo dos resultados da conduta, agindo sobre a vontade e o esforço empreendido para a obtenção de êxito (Andreu, Pallarés, \& Juárez, 2004; Bandura, 1997; Navarro, 2007). Desse modo, os níveis de autoeficácia podem incrementar ou comprometer a motivação, visto que as pessoas que carregam dúvidas sobre si encontram dificuldades para se motivarem (Schwarzer \& Schmitz, 2004), pois, quando não existe a crença de que suas açóes podem promover os resultados almejados e evitar os indesejados, carecem de incentivo e de perseverança para atuar e enfrentar obstáculos, de maneira que qualquer fator motivacional carrega em seu cerne o senso de que a conduta pode promover a mudança/resultado que se pretende (Bandura, 2004, 2008). Bandura (1997) afirma que as melhores habilidades podem ser invalidadas por dúvidas pessoais sobre a própria capacidade de realização e, por isso, pessoas diferentes com habilidades semelhantes ou a mesma pessoa em circunstâncias distintas podem exibir desempenhos extremamente variados. Da mesma forma, indivíduos altamente talentosos podem apresentar realizaçóes que estejam aquém de suas capacidades, quando suas crenças de autoeficácia estão deterioradas. 
Na medida em que a autoeficácia exerce influência sobre o comportamento humano, a prática docente não teria como estar isenta de seus efeitos, pois a autoeficácia desempenha uma funçáo mediadora nessa prática, porque age sobre os aspectos cognitivos, motivacionais e comportamentais dos educadores, influenciando suas escolhas, a persistência diante dos obstáculos, a motivação para certos comportamentos e os sentimentos ligados às escolhas feitas. "Por exemplo, professores com elevada auto-eficácia para utilização de filmes como estratégia de aula persistirão mais na discussão de filmes complexos que professores com baixa auto-eficácia” (Azzi, Polydoro, \& Bzuneck, 2006, p. 151). Além de estar relacionada às opçóes didáticas e à maneira de conduzir o processo educativo, a autoeficácia docente está associada ao sucesso acadêmico dos alunos (Bandura \& Pajares, 2007), às suas aspiraçóes e concepçóes a respeito de si (Bandura, 1997), sendo esta uma das características docentes mais impactantes sobre o rendimento estudantil (Navarro, 2007).

Tschannen-Moran e Woolfolk Hoy (2001) compreendem a autoeficácia docente como a avaliação do professor acerca de suas próprias capacidades para ensinar e motivar a todos os alunos, independentemente das dificuldades que estes possam apresentar. Suas fontes são as mesmas que as de autoeficácia geral: experiências de domínio, experiências vicárias, persuasão verbal ou social e estados fisiológicos e afetivos. A importância de seu fortalecimento decorre das implicaçóes das crenças do professor em suas capacidades docentes sobre a condução do processo ensino-aprendizagem.

As dificuldades presentes no processo de ensino-aprendizagem são entendidas pelos professores com crenças robustas, em suas capacidades docentes, como entraves superáveis, a partir de engenhosidade e esforço adicional, em vez de depositar a responsabilidade pelo insucesso da aprendizagem no estudante (Bandura, 1997). Dentre os muitos desafios que os educadores enfrentam, enfatizamos a inclusão escolar, vastamente amparada por nossa legislação (Lei no 9.394, de 20 de dezembro de 1996); contudo, distante de efetivar-se com qualidade e garantia de aprendizagem e desenvolvimento para todos (Carvalho, 2016). Apesar de a inclusão ser um compromisso assumido há mais de duas décadas, ainda é vista com certo estranhamento, pois a diversidade estudantil e o rompimento com a padronização escolar estão sendo integrados ao imaginário social processualmente. Como consequência, desafiam os professores a desconstruírem concepçóes e práticas, nem sempre amparados por condiçóes favoráveis em termos de estrutura física, número de alunos, recursos humanos e materiais disponíveis, formação continuada etc.

Considerando as dificuldades de nosso sistema educacional em concretizar a inclusão do público da Educação Especial (Carvalho, 2016), assim como as implicações desse processo aos professores (Vitaliano \& Valente, 2010), ressaltamos a relevância dos instrumentos capazes de mensurar a autoeficácia docente para um ensino inclusivo, a fim de que possam orientar as intervençóes necessárias, em especial as de caráter formativo, porque, conforme Bzuneck (1996), a compreensão adequada dos aspectos comportamentais e motivacionais docentes requer a identificação das crenças de autoeficácia dos professores, principalmente quando há a intenção de promover mudanças em suas práticas pedagógicas. Nesse sentido, o objetivo desta pesquisa é analisar as propriedades psicométricas da versão brasileira da Teacher Efficacy for Inclusive Practices (TEIP) Scale (Sharma, Loreman, \& Forlin, 2012). 


\section{Método}

Inicialmente, contatamos o primeiro autor da TEIP via e-mail, para solicitar a autorização para traduzi-la e adaptá-la à realidade brasileira. A autorização foi imediata e acompanhada do pedido de uma devolutiva, ao final da pesquisa. A tradução e a adaptação transcultu$\mathrm{ral}^{4}$ do instrumento seguiram os passos sugeridos por Guillemin, Bombardier e Beaton (1993).

O processo de validação envolveu 40 escolas, divididas em públicas estaduais, municipais e particulares, de Educação Infantil (etapas finais, pré-escolares), Ensino Fundamental I e II, das cidades de Corumbá e Ladário, no estado do Mato Grosso do Sul, Brasil.

A versão em português, denominada Escala de Eficácia Docente para Práticas Inclusivas (EEDPI), foi respondida por 346 professores. Trata-se de uma amostra de conveniência, não aleatória. Descartamos 38 escalas preenchidas, por estarem incompletas, resultando em um total de 308 instrumentos analisados. A distribuição das variáveis foi examinada com o teste de Kolmogorov-Smirnov, que revelou a não normalidade das distribuiçóes $(\mathrm{p}<0,001)$.

\subsection{CARACTERIZAÇÁo dos PARTICIPANTES}

Entre os 308 participantes, a maioria (259) era do gênero feminino, correspondendo a $84,09 \%$ da amostra. As idades variavam de 20 a 66 anos, com mediana de 39 anos, primeiro quartil (Q1) de 32, e terceiro quartil (Q3) de 47 anos. Com relação ao tempo de atuação no magistério, tivemos uma variação de menos de um a 37 anos de exercício da profissão, sendo a mediana de 10 anos, com Q1 de 5,75 e Q3 de 20 anos. A seguir, a Tabela 1 indica a distribuição dos professores segundo a formação inicial.

\begin{tabular}{l|c|c}
\hline \multicolumn{1}{c}{ Formaçáo inicial } & n & \% \\
\hline Pedagogia & 135 & 43,83 \\
Licenciatura & 115 & 37,34 \\
Magistério e Pedagogia & 37 & 12,01 \\
Magistério e Licenciatura & 13 & 4,22 \\
Pedagogia e Licenciatura & 4 & 1,30 \\
Magistério & 4 & 1,30 \\
\hline Total & $\mathbf{3 0 8}$ & $\mathbf{1 0 0 , 0 0}$ \\
\hline
\end{tabular}

Tabela 1. Distribuição dos professores participantes de acordo com a formação inicial apresentada.

Fonte: Elaborada pelos autores.

Ainda no que se refere à formação, 151 professores (49,02\%) possuíam curso de PósGraduação em nível lato sensu, dos quais 12 (3,9\%) eram especialistas em Educação Especial ou Educação Inclusiva. Além disso, 18 professores (5,84\%) tinham titulação de mestre e/ou doutor na área da Educação ou em outras áreas relacionadas à formação inicial.

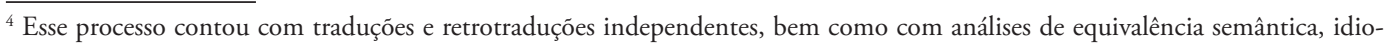
mática, de conteúdo e de conceito realizadas por um comitê composto por pesquisadoras e profissionais da Educação com conhecimentos em língua inglesa.
} 
Um total de 186 professores (60,39\%) relatou ter trabalhado com o público da Educação Especial, em algum momento. Em relação ao tipo de administração institucional, 213 professores eram de escolas municipais; 54, de escolas estaduais; e, 41, de escolas privadas. A maioria dos professores atuava no Ensino Fundamental I (51,1\%); em seguida, no Ensino Fundamental II (30,5\%); e, em menor número, na Educação Infantil (18,4\%).

\subsection{INSTRUMENTOS}

Os participantes do estudo foram convidados a preencher uma ficha de caracterização, a EEDPI e a Escala de autoeficácia de professores: versão breve, elaborada por TschannenMoran e Woolfolk Hoy (2001). Ambas as escalas são do tipo Likert e apresentam seis opções de resposta em cada enunciado.

A versão da EEDPI respondida pelos participantes, tal como a versão original em inglês, continha 18 itens destinados a mensurar a autoeficácia docente para desenvolver práticas escolares inclusivas, abrangendo a utilização de estratégias educacionais que promovem a inclusão, o manejo de comportamentos em sala de aula e o trabalho conjunto a familiares e a outros profissionais.

A Escala de autoeficácia de professores: versão breve (Tschannen-Moran \& Woolfolk Hoy, 2001), com 12 itens, foi traduzida, adaptada e utilizada por Casanova (2013) e Almeida (2016) com professores do Ensino Fundamental e Médio, tendo sido validada por Análise Fatorial Exploratória em ambos os estudos. A aplicação dessa escala ocorreu para verificar a validade de critério da EEDPI, isto é, para avaliar o grau de eficácia do teste em medir o que se propôe, a partir da relação com um critério externo (Souza, Alexandre, \& Guirardello, 2017); no caso, a Escala de autoeficácia de professores: versão breve, considerada "padrão-ouro".

A validade de critério de um teste-alvo (em avaliação) é analisada comparando-se seus resultados a um "padrão-ouro" ou teste de critério, quer dizer, uma medida amplamente aceita que possui as mesmas características do teste-alvo. Quando os resultados de ambos concordam, significa que o teste-alvo mede o que se pretende medir (Souza, Alexandre, \& Guirardello, 2017).

A opção pela Escala de autoeficácia de professores: versáo breve deu-se porque, segundo Woolfolk Hoy e Burke-Spero (2005), essa escala é "superior às medidas anteriores de eficácia do professor” (p. 354, tradução nossa). Klassen, Tze, Betts e Gordon (2011) afirmam que as versões curta e longa da escala do senso de eficácia do professor, criadas por Tschannen-Moran e Woolfolk Hoy (2001), estão entre as que melhor atendem aos pressupostos da teoria e, por isso, são bem recomendadas, tendo sido usadas em 16 estudos publicados na década em que Klassen et al. (2011) as revisaram. No Brasil, chegou-se também à resolução de três fatores, como no original: Autoeficácia para engajamento do estudante, estratégias instrucionais e manejo de sala de aula (Almeida, 2016; Casanova, 2013).

\subsection{Procedimentos Para a coleta de dados}

Fomos pessoalmente a cada uma das 40 escolas, conversamos com os gestores, para explicar os propósitos do estudo, e pedimos autorização para convidar os professores a parti- 
cipar da pesquisa. Em algumas instituições, não éramos autorizados a ter contato direto com os professores, de modo que deixávamos as escalas com a direção e voltávamos em data previamente acertada para buscá-las (entrega intermediada). Nesses casos, o retorno tendia a ser baixo. Em contrapartida, pudemos percorrer todas as salas de outras escolas, para conversar com os professores individualmente e entregar-lhes os instrumentos (entrega direta). Dessa maneira, conseguíamos uma devolutiva maior, pois tínhamos um controle dos professores que haviam ou não entregado, e retornávamos várias vezes ao local, para buscar as escalas com aqueles que esqueciam ou precisavam de mais tempo para respondê-la. Mesmo assim, a taxa de devolução foi baixa, já que havíamos distribuído cerca de 750 instrumentos.

\subsection{ANÁlISE DOS DADOS}

Usamos a planilha eletrônica Microsoft Excel, do pacote Office, versão 2013, para a sistematização dos dados, e o pacote estatístico IBM Statistical Package for Social Sciences (SPSS), em sua versão 22.0, para a realização de análises estatísticas.

A EEDPI foi submetida aos seguintes procedimentos analíticos: realizamos os testes Kaiser-Meyer-Olkin (KMO) e de esfericidade de Bartlett, a fim de avaliar a validade da análise fatorial exploratória (AFE). Tendo obtido bons resultados, avaliamos a estrutura relacional com base na AFE, com extração dos componentes principais, seguida de rotação Varimax. Inicialmente, optou-se pela retenção dos componentes com eigenvalue superior a 1, considerando-se, ainda, o Scree plot, pois o estabelecimento de critério único pode ocasionar a retenção de mais ou menos fatores que os necessários à descrição da estrutura latente (Marôco, 2014). Essa decisão levou-nos, em um segundo momento, a fixar o número de fatores a serem extraídos.

Para que o item fosse incluído em um fator, deveria apresentar um coeficiente maior do que 0,45 de carga fatorial. Com base em Comrey e Lee (1992), Laros (2005) esclarece que cargas fatoriais maiores que 0,71 são consideradas excelentes, assim como as maiores que 0,63 são tidas como muito boas, as que superam 0,55 são boas e as maiores que 0,45 são regulares; cargas fatoriais menores que 0,45 são consideradas pobres.

A análise da consistência interna do instrumento deu-se por meio do Coeficiente de Alfa de Cronbach, considerando-se aceitáveis os coeficientes a partir de 0,70. Ainda, aplicou-se a Análise de Correlação de Spearman $\left(\mathrm{R}_{\mathrm{s}}\right.$ ) com o intuito de verificar os níveis de relacionamento entre as variáveis das escalas. Ademais, aceitou-se o nível de significância de 0,05.

Atribuiu-se uma pontuação individual às escalas de cada participante, a partir da média das respostas, dividindo-se o escore total pelo número de itens, de maneira que tanto a EEDPI quanto a Escala de autoeficácia de professores: versáo breve recebesse no mínimo 1 e no máximo 6 pontos, favorecendo a comparação entre elas, proveniente da análise das variações, medianas e intervalos interquartis.

\section{Resultados}

A distribuição dos resultados nos itens da escala mostrou-se adequada para a efetivação da análise fatorial, apresentando KMO de 0,90 e teste de esfericidade de Bartlett de $\mathrm{X}^{2}=$ $3363,13$ ( $\mathrm{gl}=153, \mathrm{p}<0,001)$, considerado altamente significativo. 
A opção foi fazer a análise dos componentes principais, diferindo os fatores a isolar com base no eigenvalue igual ou superior à unidade. Tal análise concluiu por três fatores, todos com valores acima de 1, corroborando os achados de Sharma, Loreman e Forlin (2012), na construção de sua versão original, porém com organização distinta. A relevância desses três fatores pode encontrar-se no gráfico de declividade (Scree Plot), como se vê na Figura 1.

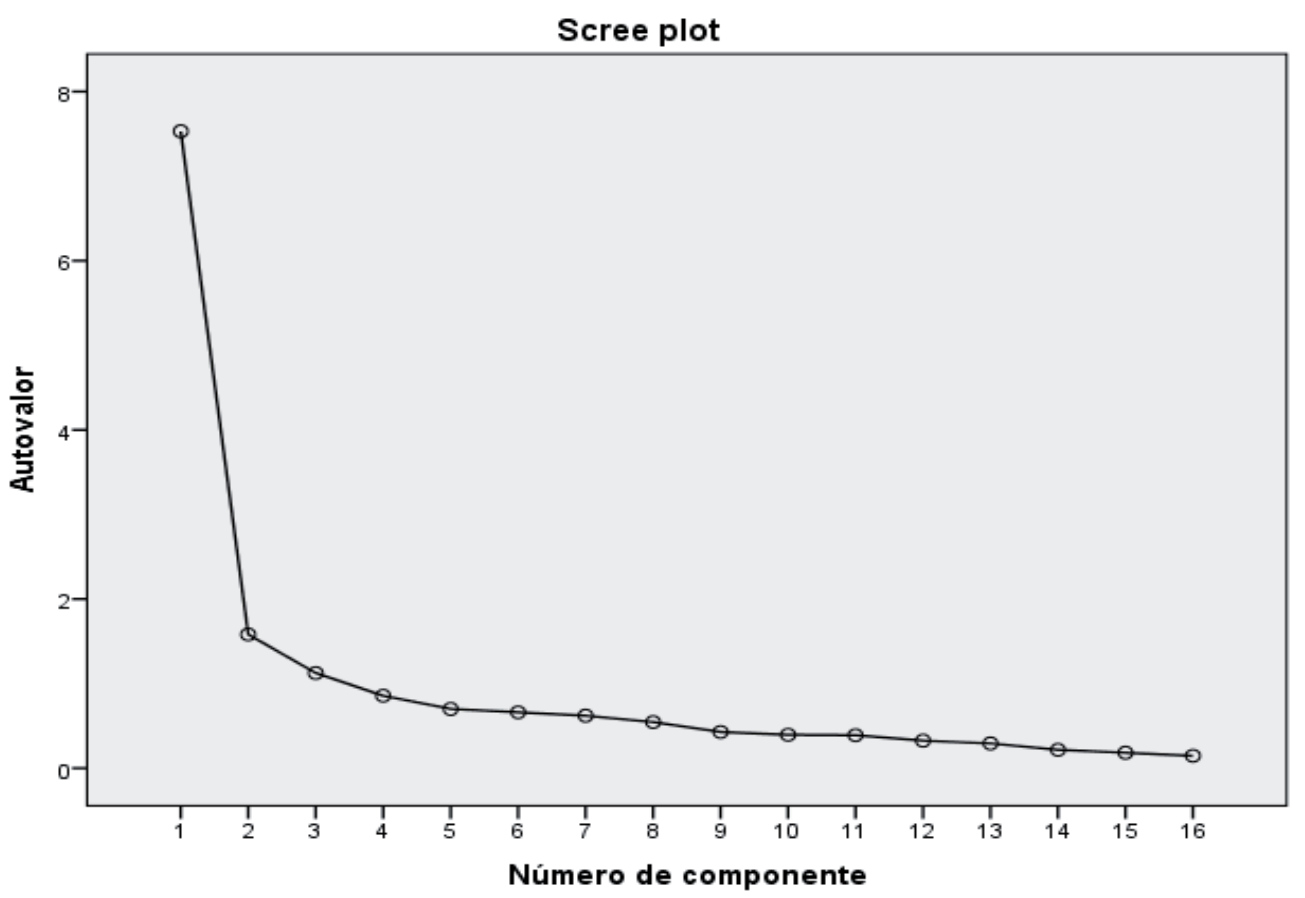

Figura 1. Declividade com os componentes principais da Escala de Eficácia Docente para Práticas Inclusivas.

Fonte: Elaborada pelos autores a partir do software SPSS.

Os três fatores obtidos na AFE explicaram 62,27\% da variância total. Ao analisarmos o conteúdo dos itens agrupados no primeiro fator, verificamos que todos eles se relacionavam com os comportamentos do professor, em termos de regência de sala de aula (evitar comportamentos inapropriados, avaliar a compreensão do estudante, propor desafios adequados etc.), explicando 46,96\% da variância. O segundo fator, o qual agrupou os itens ligados a alunos com demandas específicas (alunos agressivos, confusos, com deficiência), explicava 8,82\% da variância. O Fator 3, cujo conteúdo se referia à relação com as famílias, explicou $6,50 \%$ da variância total.

A despeito de o número de fatores obtidos ser idêntico ao da escala original, a tipologia dos itens, em cada um deles, e a significação por nós atribuída às três dimensóes diferem substancialmente. Ao mesmo tempo, um dos fatores aponta para dois itens (Fator 3), havendo ainda o item 18 (fornecer exemplos e explicaçóes alternativas quando os alunos estão confusos), 
que extraiu o mesmo valor em dois fatores, semelhantemente ao item 9 (capacidade de envolver os pais nas atividades escolares dos seus filhos com deficiência), com dupla saturação.

Embora a relevância do terceiro fator seja apontada pelo gráfico de declividade (Figura 1), Tabachnick e Fidell (2013) recomendam cautela na interpretação de fatores definidos por apenas dois itens, em virtude de sua confiabilidade questionável. Aliás, seria inexpressivo manter uma dimensão com tấo poucos itens. Simultaneamente, a interação entre a escola e a família é de suma importância para o processo de ensino e aprendizagem, sobretudo na inclusão escolar, o que não justificaria a exclusão desses itens. Assim, empreendemos uma nova análise, com a fixação da extração de dois fatores.

A partir da análise dos pesos fatoriais com a delimitação da extração de dois fatores, obtivemos a explicação de $55,78 \%$ da variância. A saturação dos itens variou de 0,45 a 0,82 , enquanto a comunalidade dos itens 1,3 e 4 foi menor que $50 \%(0,36,0,33$ e 0,35), indicando pouca variância comum nessas variáveis, porém dentro do nível tido por aceitável (Tabachnick \& Fidell, 2013).

A reestruturação da escala, a partir da fixação de dois fatores, resolveu a dupla saturação do item 9. Entretanto, o item 18 permaneceu com alta saturação nos fatores 1 e 2 e surgiu outro item carregado em ambos, o de número 14. O item $18 \mathrm{diz}$ respeito ao oferecimento de outras explicaçóes ou exemplos, quando os alunos estáo confusos, de modo que julgamos adequado excluí-lo. Já o item 14, que concerne ao trabalho conjunto entre os estudantes, foi considerado indispensável, tanto pela importância do outro na aprendizagem quanto por ser a existência de interação social positiva um dos indicadores da inclusão escolar bem-sucedida.

Em prosseguimento, o conteúdo e a relação entre os itens de cada fator foram analisados. Tem-se, por conseguinte, o primeiro fator com pesos fatoriais elevados nos enunciados referentes à gestão de comportamentos e estratégias de ensino, sendo designado "Regência de sala de aula". O segundo fator demonstra altas cargas fatoriais nas habilidades para trabalhar conjuntamente a outros profissionais e planejar atividades, designado "Planejamento e colaboração". Nessa altura, percebemos a inadequação do item 17 , o qual se referia a maneiras de lidar com alunos agressivos fisicamente. Outrossim, os idealizadores da versão original do instrumento certamente atrelaram a possibilidade de agressão às particularidades de certos públicos pertencentes à Educação Especial. No entanto, a educação brasileira é marcada pelas lamentáveis situações em que professores são vítimas de agressões verbais e físicas, por parte de seus alunos (Soares \& Machado, 2014), o que torna pouco provável a total concordância dos educadores com a afirmação "sinto-me confiante para lidar com alunos fisicamente agressivos". Diante da pouca coerência desse enunciado com os itens restantes da dimensão, decidimos por sua eliminação.

A adequabilidade do item 15 também chegou a ser questionada, pois este está relacionado ao uso de estratégias de avaliação diversificadas, cabendo na dimensão "Regência de sala de aula”. Contudo, uma avaliação diversificada ultrapassa a aplicação de provas e a observação direta do comportamento, podendo envolver as famílias e outros profissionais, principalmente no que tange ao aluno público da Educação Especial. Além de exigir planejamento, reflexão e tomada de decisão, são processos que não estão restritos ao espaço da sala de aula, justificando sua aproximação aos demais itens do Fator 2, atinentes a atividades docentes desempenhadas fora de sala de aula (planejamento, relacionamento com os pais, trabalho colaborativo com outros profissionais, conhecimento sobre a legislação inclusiva). 
$\mathrm{Na}$ realização da AFE da versão com 16 itens, mantivemos a opção pela extração dos componentes principais, com a fixação de dois fatores e rotação Varimax. Com base nessa análise, tem-se a explicação de 56,95\% da variância total. A Tabela 2 sistematiza os resultados obtidos.

\begin{tabular}{|c|c|c|c|c|}
\hline No & Item & Fator 1 & Fator 2 & $\mathbf{h}^{2}$ \\
\hline 1 & $\begin{array}{l}\text { Consigo deixar claro, aos alunos, quais minhas expectativas em relação aos seus } \\
\text { comportamentos. }\end{array}$ & 0,56 & & 0,36 \\
\hline 2 & Sou capaz de acalmar um aluno perturbador/barulhento. & 0,74 & & 0,61 \\
\hline 3 & Consigo fazer com que os pais se sintam à vontade para vir à escola. & & 0,47 & 0,35 \\
\hline 4 & $\begin{array}{l}\text { Consigo auxiliar as famílias para que ajudem seus filhos a irem bem na escola } \\
\text { (em relaçâo à aprendizagem, à interaçấo e ao comportamento). }\end{array}$ & & 0,49 & 0,37 \\
\hline 5 & Consigo avaliar com precisão a compreensão do aluno em relaçáo ao que ensinei. & 0,68 & & 0,60 \\
\hline 6 & Consigo propor desafios adequados a alunos muito capazes. & 0,67 & & 0,51 \\
\hline 7 & $\begin{array}{l}\text { Tenho confiança em minha habilidade de evitar a ocorrência de comportamen- } \\
\text { tos perturbadores em sala de aula. }\end{array}$ & 0,82 & & 0,72 \\
\hline 8 & Consigo controlar comportamentos perturbadores em sala de aula. & 0,82 & & 0,70 \\
\hline 9 & $\begin{array}{l}\text { Tenho confiança na minha capacidade de envolver os pais nas atividades escola- } \\
\text { res dos seus filhos com deficiência. }\end{array}$ & & 0,77 & 0,66 \\
\hline 10 & $\begin{array}{l}\text { Tenho confiança em planejar atividades educacionais para que as necessidades } \\
\text { individuais dos alunos com deficiência sejam adequadamente atendidas. }\end{array}$ & & 0,74 & 0,63 \\
\hline 11 & Sou capaz de fazer com que as crianças sigam as regras da sala de aula. & 0,75 & & 0,63 \\
\hline 12 & $\begin{array}{l}\text { Consigo trabalhar em colaboração com outros profissionais (por exemplo, pro- } \\
\text { fessores itinerantes; especialistas; professor do AEE; intérprete de LIBRAS etc.) } \\
\text { na elaboraçāo de planos educacionais para alunos com deficiência. }\end{array}$ & & 0,78 & 0,65 \\
\hline 13 & $\begin{array}{l}\text { Sou capaz de trabalhar em conjunto a outros profissionais e funcionários (por } \\
\text { exemplo, auxiliares, outros professores) para ensinar alunos com deficiência em } \\
\text { sala de aula. }\end{array}$ & & 0,80 & 0,68 \\
\hline 14 & $\begin{array}{l}\text { Tenho confiança em minha habilidade de fazer com que os alunos trabalhem } \\
\text { juntos em pares ou em pequenos grupos. }\end{array}$ & 0,58 & & 0,56 \\
\hline 15 & $\begin{array}{l}\text { Sou capaz de usar uma variedade de estratégias de avaliaçấo (por exemplo, ava- } \\
\text { liaçấo do portfólio, testes adaptados, avaliaçáo baseada em desempenho, etc.). }\end{array}$ & & 0,63 & 0,58 \\
\hline 16 & $\begin{array}{l}\text { Tenho confiança em fornecer informaçóes sobre as leis e as políticas relacionadas à } \\
\text { inclusão de alunos com deficiência às pessoas que conhecem pouco desse assunto. }\end{array}$ & & 0,69 & 0,51 \\
\hline & Número de itens & 8 & 8 & \\
\hline & eigenvalue & 7,53 & 1,58 & \\
\hline & \% da Variância & 47,07 & 9,88 & \\
\hline & Alfa de Cronbach & 0,89 & 0,88 & 0,92 \\
\hline
\end{tabular}

Tabela 2. Distribuição das cargas fatoriais, comunalidades, eigenvalue dos fatores, porcentagem de variância explicada e índices de consistência interna da Escala de Eficácia Docente para Práticas Inclusivas com 16 itens.

Fonte: Elaboração própria. 
O Fator 1 representa 47,07\% da variância total e carrega oito itens ligados à "Regência em sala de aula". O Fator 2 explica 9,88\% e contempla os itens associados a "Planejamento e colaboração". O Alfa de Cronbach da escala com 16 itens foi de 0,92, com 0,89 para o Fator 1 e 0,88 para o Fator 2, evidenciando alta consistência interna. No caso da exclusão de qualquer um dos itens dessa resolução, o Alfa de Cronbach permaneceria em 0,92. Dessa maneira, propóe-se o uso dessa versão da Escala de Eficácia Docente para Práticas Inclusivas com 16 itens, a qual se mostra detentora de propriedade psicométricas adequadas.

$\mathrm{Na}$ sequência, analisamos descritivamente as frequências dos dados obtidos no preenchimento das duas escalas.

\subsection{Relacionando AS ESCALAS}

A Escala de autoeficácia de professores: versão breve possui 12 itens, de modo que o respondente deveria assinalar um número de um a seis, conforme o quanto se julgava eficaz para cada atividade educacional. Pela somatória dos pontos atribuídos aos itens, tem-se um escore individual que pode variar de 12 a 72. A EEDPI também apresenta seis opçóes de resposta, representando o número um total discordância da afirmativa; e o número seis, sua total concordância. Contendo 16 itens, a pontuação individual pode variar de 16 a 96. Com o intuito de favorecer a comparação entre os resultados dos instrumentos, escolhemos atribuir, tal como Bzuneck (1996), ao aplicar a escala de Woolfolk e Hoy (1990), uma pontuação obtida a partir de uma medida de tendência central, no caso, a média. Perante a distribuição não normal de nossa amostra, calculamos as medianas das escalas e subescalas cujas pontuaçóes poderiam oscilar entre 1 a 6 .

Bzuneck (1996) interpretou a escala de seis pontos, cujas alternativas expressavam de total discordância a total concordância, em função de três intervalos: médias inferiores a três foram consideradas baixas; a partir de três e menores que cinco, intermediárias, e médias entre cinco e seis foram classificadas como altas. Diferentemente, optamos por interpretar os resultados utilizando cinco intervalos, ao compreender que uma pontuação entre 1 e 1,99 se localiza entre a discordância e a total discordância em relação ao senso de eficácia, o que significa autoeficácia muito baixa; escores entre 2 e 2,99 representam a variação entre discordância e discordância parcial, de maneira a evidenciar autoeficácia baixa; entre 3 e 3,99 pontos, tem-se a oscilação entre discordância e concordância parciais, interpretada como autoeficácia média; entre 4 e 4,99, nota-se a alternância entre "concordo parcialmente" e "concordo", compreendida como autoeficácia alta, e a variação entre 5 e 6 pontos, ao situar-se entre a concordância e a total concordância, representa autoeficácia muito alta. Nas Tabelas 3 e 4, são sintetizados os resultados das escalas.

\begin{tabular}{lccc}
\hline \multicolumn{1}{c}{ Dimensóes } & $\begin{array}{c}\text { Variaçáo } \\
(\mathbf{m i n}-\mathbf{m a x})\end{array}$ & Mediana & $\begin{array}{c}\text { Dispersáo } \\
(\mathbf{Q 1}-\mathbf{Q 3})^{*}\end{array}$ \\
\hline Engajamento estudantil & $1,50-6$ & 5,00 & $5,75-4,50$ \\
Manejo de classe & $2,06-6$ & 4,94 & $5,55-4,31$ \\
Estratégias instrucionais & $2,50-6$ & 4,75 & $5,50-4,25$ \\
\hline Escala completa & $2,67-6$ & 4,92 & $5,42-4,33$ \\
\hline
\end{tabular}

Tabela 3. Pontuações obtidas na Escala de autoeficácia de professores: versão breve.

Fonte: Elaborada pelos autores.

Nota: * Intervalo Interquartil. 


\begin{tabular}{lccc}
\hline \multicolumn{1}{c}{ Dimensóes } & $\begin{array}{c}\text { Variaçáa } \\
(\mathbf{m i n}-\mathbf{m a x})\end{array}$ & Mediana & $\begin{array}{c}\text { Dispersão } \\
(\mathbf{Q 1}-\mathbf{Q 3})^{*}\end{array}$ \\
\hline Regência de sala de aula & $2,63-6$ & 5,00 & $5,50-4,63$ \\
Planejamento e colaboração & $1,75-6$ & 4,88 & $5,25-4,38$ \\
\hline Escala completa & $2,56-6$ & 4,94 & $5,37-4,50$ \\
\hline
\end{tabular}

Tabela 4. Pontuações obtidas na Escala de Eficácia Docente para Práticas Inclusivas.

Fonte: Elaborada pelos autores.

Nota: * Intervalo Interquartil.

Ao considerarmos os escores das escalas completas exibidos nas Tabelas 3 e 4, notamos que, genericamente, os professores participantes do estudo revelam autoeficácia em nível alto, tanto para práticas inclusivas (EEDPI) quanto para práticas pedagógicas, de modo geral, indicando que há uma relaçáo positiva entre a autoeficácia docente para o ensino e a autoeficácia docente para a inclusáo de alunos com necessidades especiais. Nessa perspectiva, supóe-se que as escalas medem o mesmo constructo: a autoeficácia.

A pontuação mediana obtida na EEDPI pelo conjunto de professores em nossa amostra é compatível com o nível de autoeficácia apresentado por professores de outros países, em resposta à versão original da TEIP: Canadá, 4,51, Austrália, 4,53 e Bangladeshi, 4,84, sendo mais elevada que a apresentada por professores da Indonésia, 4,38 e da China, 3,93 (Ahsan, Deppeler, \& Sharma, 2013; Loreman, Sharma, \& Forlin, 2013). A esse respeito, para além da diversidade contextual, Loreman, Sharma e Forlin (2013) enfatizam as diferenças culturais existentes, as quais náo podem ser generalizadas entre Oriente versus Ocidente, pois existem peculiaridades regionais, e até mesmo individuais, no que se refere aos distintos países.

$\mathrm{Na}$ sequência, verificamos o grau de relacionamento existente entre as variáveis das escalas, por meio da Análise de Correlação de Spearman, conforme mostra a Tabela 5.

\begin{tabular}{|c|c|c|c|c|c|}
\hline Variável & $\begin{array}{c}{[\mathrm{E} 1]} \\
\text { Engajamento } \\
\text { estudantil }\end{array}$ & $\begin{array}{c}\text { ME1] } \\
\text { Manejo de } \\
\text { classe }\end{array}$ & $\begin{array}{c}{[\mathrm{E} 1]} \\
\text { Estratégias } \\
\text { instrucionais }\end{array}$ & $\begin{array}{c}{[\mathrm{E} 2]} \\
\text { Regência de } \\
\text { sala de aula }\end{array}$ & $\begin{array}{c}{[\mathrm{E} 2]} \\
\text { Planejamento e } \\
\text { colaboraçáo }\end{array}$ \\
\hline $\begin{array}{l}\text { [E1] } \\
\text { Engajamento } \\
\text { estudantil }\end{array}$ & 1 & & & & \\
\hline $\begin{array}{l}{[\text { E1] }} \\
\text { Manejo de classe }\end{array}$ & $+0,71^{*}$ & 1 & & & \\
\hline $\begin{array}{l}{[\text { E1] }} \\
\text { Estratégias } \\
\text { instrucionais }\end{array}$ & $+0,67^{*}$ & $+0,57^{*}$ & 1 & & \\
\hline $\begin{array}{l}{[\mathrm{E} 2]} \\
\text { Regência de sala } \\
\text { de aula }\end{array}$ & $+0,58^{*}$ & $+0,52^{*}$ & $+0,49^{*}$ & 1 & \\
\hline
\end{tabular}




\begin{tabular}{|c|c|c|c|c|c|}
\hline Variável & $\begin{array}{c}{[\mathrm{E} 1]} \\
\text { Engajamento } \\
\text { estudantil }\end{array}$ & $\begin{array}{l}{[E 1]} \\
\text { Manejo de } \\
\text { classe }\end{array}$ & $\begin{array}{c}{[\mathrm{E} 1]} \\
\text { Estratégias } \\
\text { instrucionais }\end{array}$ & $\begin{array}{l}{[E 2]} \\
\text { Regência de } \\
\text { sala de aula }\end{array}$ & $\begin{array}{c}{[\mathrm{E} 2]} \\
\begin{array}{c}\text { Planejamento e } \\
\text { colaboraçáo }\end{array}\end{array}$ \\
\hline $\begin{array}{l}{[\mathrm{E} 2]} \\
\text { Planejamento e } \\
\text { colaboração }\end{array}$ & $+0,60^{*}$ & $+0,41^{*}$ & $+0,49^{*}$ & $+0,70^{*}$ & 1 \\
\hline
\end{tabular}

Tabela 5. Matriz de correlação entre as variáveis emergidas nas Análises fatoriais das duas escalas Fonte: Elaborada pelos autores.

Notas:

${ }^{*} \mathrm{p}<0,001$

E1 - Escala de autoeficácia de professores: versão breve.

E2 - Escala de Eficácia Docente para Práticas Inclusivas.

A Tabela 5 exibe um alto nível de significância $(\mathrm{p}<0,001)$ entre as correlaçóes, com $\mathrm{n}=308$. As variáveis da Escala de autoeficácia de professores: versão breve correlacionam-se forte e positivamente, com coeficientes de 0,71, 0,67 e 0,57. As subescalas da Escala de Eficácia Docente para Práticas Inclusivas também demonstram forte correlação positiva com $\mathrm{R}_{\mathrm{S}}=0,70$. $\mathrm{Na}$ correlação entre as subescalas dos dois instrumentos, encontramos os coeficientes 0,58 , $0,52,0,49,0,60,0,41,0,49$, que nos permitem perceber a existência de uma correlação positiva, oscilando de moderada à forte.

A moderada correlação entre as duas escalas pode ser interpretada como um resultado da especificidade de cada uma, porque, embora ambas se destinem a mensurar a autoeficácia docente, a Escala de autoeficácia de professores: versáo breve aborda a docência de maneira geral, ao passo que a EEDPI se volta para as práticas educacionais inclusivas. A relevância de uma escala que avalie a autoeficácia docente destinada à inclusão escolar justifica-se pelos conhecimentos e pelas habilidades que o professor precisa ter, para atender, educacionalmente, às particularidades do processo de ensino e de aprendizagem do público da Educaçáo Especial, que podem demandar diferenciaçóes metodológicas, curriculares, materiais e instrucionais (Loreman, Sharma, \& Forlin, 2013).

A correlação positiva entre a EEDPI e a escala tomada como "padrão-ouro" atesta sua validade de critério, visto que, de fato, o instrumento mede o que se propóe medir. Assim, estabelece-se como uma ferramenta de avaliação da autoeficácia docente para práticas inclusivas, no Brasil. De acordo com Bzuneck (1996), antes de tentar exercer influência sobre o comportamento dos professores, é recomendável iniciar com a identificação de suas crenças, em especial, as de autoeficácia.

As açôes dos indivíduos estão mais ligadas às crenças que possuem acerca de suas capacidades (autoeficácia) do que às capacidades em si, uma vez que são essas crenças que direcionam as realizaçóes. Segundo Navarro (2007), nem sempre as crenças correspondem à realidade, de modo que existem pessoas que carregam dúvidas sobre suas capacidades, mesmo que claramente as possuam, enquanto outras acreditam completamente que são eficazes em condutas para as quais lhes faltam destrezas. A crença na própria eficácia não é garantia de 
sucesso, porém propicia a motivação necessária para iniciar e persistir em determinada ação, visando aos resultados desejados.

As crenças de autoeficácia correspondem àquilo que o indivíduo acredita a respeito de suas habilidades para realizar uma tarefa específica (Azzi \& Polydoro, 2006). Para Navarro (2007):

Os professores mostram-se eficazes para ensinar uma determinada matéria a certos alunos e em uma situação específica, e estas crenças podem variar em condiçóes distintas. Por conseguinte, para emitir um juízo sobre a autoeficácia do professor é necessário se levar em conta a atividade docente específica e o contexto em que esta se desenvolve. (p. 133).

A autoeficácia docente influi na maneira como o professor pensa a respeito de si, de sorte a atuar sobre a tendência ao otimismo ou ao pessimismo, a motivação, o enfrentamento a situaçóes difíceis e as escolhas empreendidas (Navarro, 2007). Trata-se, assim, de um constructo de grande importância para a inclusão escolar, devido ao seu papel regulador das práticas de ensino (Loreman, Sharma, \& Forlin, 2013).

Nesse sentido, é imperioso primar pelo fortalecimento da autoeficácia dos professores, pois, embora esta, por si só, não seja garantia de bons resultados, sua ausência afeta o início, o esforço e a persistência em tarefas para as quais se julgam inaptos.

\section{Consideraçótes finais}

A autoeficácia docente desempenha uma importante função na regulação do comportamento do professor ao exercer influências sobre sua dedicação, desempenho e incentivo aos alunos durante a condução do processo de ensino e aprendizagem. Por tratar-se de um conceito específico, um professor pode sentir-se hábil para o desenvolvimento de determinada tarefa e ineficiente para outra; desse modo, o fato de acreditar em suas capacidades para o ensino da matemática não significa que suas crenças relacionadas ao ensino de artes sejam positivas. Transpondo o argumento para o contexto da educaçáo inclusiva, um professor com autoeficácia elevada para o trabalho pedagógico, de um modo geral, pode sentir-se incapaz de ensinar um estudante pertencente ao público da Educação Especial. Logo, é importante mensurar a autoeficácia docente para práticas inclusivas e desenvolver as ações oportunas diante da constatação de crenças deficitárias. Sob essa perspectiva, propóe-se o uso da Escala de Eficácia Docente para Práticas Inclusivas, versão traduzida e adaptada à realidade brasileira, cujas qualidades psicométricas mostram-se adequadas. Sugere-se que a referida escala seja aplicada em diferentes contextos e populaçóes com vistas a contribuir para sua validação.

Aliás, cumpre salientar as contribuições desta pesquisa em relação ao avanço do estado da arte em termos epistemológicos, uma vez que amplia as discussóes da área da Educação Especial no Brasil ao destacar as influências das crenças de autoeficácia dos professores na efetivação da inclusão escolar e introduzir uma escala que consiste em uma nova fonte de conhecimento, com validade e confiabilidade, a qual representa o primeiro instrumento de autoeficácia docente para práticas inclusivas rigorosamente validado em âmbito nacional, o que lhe confere caráter de ineditismo. 


\section{REFERÊNCIAS}

Ahsan, M. T., Deppeler, J. M., \& Sharma, U. (2013). Predicting pre-service teachers' preparedness for inclusive education: Bangladeshi pre-service teachers' attitudes and perceived teaching-efficacy for inclusive education. Cambridge Journal of Education, 43(4), 517-535. DOI: https://doi.org/10.10 80/0305764X.2013.834036

Almeida, V. M. (2016). Autoeficácia de professores, satisfação no trabalho e atendimento das necessidades psicológicas básicas (Dissertação de Mestrado). Centro de Educação, Comunicação e Artes, Departamento de Educação, Universidade Estadual de Londrina, Londrina, PR, Brasil.

Andreu, L., Pallarés, À., \& Juárez, Ó. (2004). La incidência del entrenamiento en el nível de eficácia percebida: un estudio en un equipo feminino de fútbol. In M. Salanova, R. Grau, I. M. Martínez, E. Cifre, S. Lorens, \& M. Garcia-Renedo (Eds.), Nuevos horizontes em la investigación sobre la autoeficácia (pp. 205-211). Castelló de la Plana: Publicacions de la Universitat Jaume I, D.L.

Azzi, R. G., \& Polydoro, S. A. J. (2006). Teoria Social Cognitiva e Teoria da Auto-eficácia: desvendando relaçôes na produção de Bandura. In R. G. Azzi, \& S. A. J. Polydoro (Orgs.), Auto-eficácia em diferentes contextos (pp. 17-23). Campinas, SP: Alínea.

Azzi, R. G., Polydoro, S. A. J., \& Bzuneck, J. A. (2006). Consideraçôes sobre a auto-eficácia docente. In R. G. Azzi, \& S. A. J. Polydoro (Orgs.), Auto-eficácia em diferentes contextos (pp. 149-159). Campinas, SP: Editora Alínea.

Bandura A. (1978). Self-Efficacy: Toward a Unifying Theory of Behavioral Change. Advances in Behaviour Research and Therapy, 1,139-161.

Bandura, A. (1997). Self-efficacy: the exercise of control. New York: W.H. Freeman and Company.

Bandura, A. (2004). The growing primacy of perceived efficacy in human self-development, adaptation and change. In M. Salanova, R. Grau, I. M. Martínez, E. Cifre, S. Lorens, \& M. Garcia-Renedo (Eds.), Nuevos horizontes em la investigación sobre la autoeficácia (pp. 33-51). Castelló de la Plana: Publicacions de la Universitat Jaume I, D.L.

Bandura, A. (2008). A teoria social cognitiva na perspectiva da agência humana. In A. Bandura, R. G. Azzi, \& S. Polydoro (Eds.), Teoria social cognitiva: conceitos básicos (pp. 69-96). Porto Alegre: Artmed.

Bandura, A., \& Pajares, F. (2007). Prólogo. In L. P. Navarro (Ed.), Autoeficacia del professor universitário: Eficacia percebida e práctica docente (pp. 11-15). Madrid: Narcea, S. A. de ediciones.

Bzuneck, J. A. (1996). Crenças de auto-eficácia de professoras do $1^{\circ}$ grau e sua relação com outras variáveis de predição e de contexto. Arquivos Brasileiros de Psicologia, 48(4), 57-89.

Carvalho, R. E. (2016). Educação inclusiva: com os pingos nos “is”. Porto Alegre: Mediação.

Casanova, D. C. G. (2013). Crenças de eficácia de gestores escolares e de docentes no ensino médio paulista (Tese de Doutorado). Faculdade de Educação, Universidade Estadual de Campinas, Campinas, SP, Brasil.

Comrey, A. L., \& Lee, H. B. (1992). A first course in factor analysis. East Sussex: Psychology Press.

Guillemin, F., Bombardier, C., \& Beaton, D. (1993). Cross-cultural adaptation of health - related quality of life measures: literature review and proposed guidelines. Journal Clin. Epidemiol., 46(12), 1427-32.

Klassen, R. M., Tze, V. M. C., Betts, S. M., \& Gordon, K. A. (2011). Teacher Efficacy Research 19982009: Signs of Progress or Unfulfilled Promise? Educational Psychology Review, 23, 21-43.

Laros, J. A. (2005). O uso da análise fatorial: algumas diretrizes para pesquisadores. In L. Pasquali (Ed.), Análise fatorial para pesquisadores (pp. 141-160). Brasília: LabPAM Saber e Tecnologia. 
Lei no 9.394, de 20 de dezembro de 1996. Estabelece as diretrizes e bases da educação nacional. Recuperado em 24 de agosto de 2019 de http://www.planalto.gov.br/ccivil_03/leis/19394.htm

Loreman, T., Sharma, U., \& Forlin, C. (2013). Do pre-service teachers feel ready to teach in inclusive classrooms? A four country study of teaching self-efficacy. Australian Journal of Teacher Education, 38(1), 27-44. DOI: http://dx.doi.org/10.14221/ajte.2013v38n1.10

Marôco, J. (2014). Análise Estatística com o SPSS Statistics. Reportnumber: Perô Pinheiro.

Martínez, M. I. (2004). Autoeficacia aplicada al trabajo y a las organizaciones. In M. Salanova, R. Grau, I. M. Martínez, E. Cifre, S. Lorens, \& M. Garcia-Renedo (Eds.), Nuevos horizontes em la investigación sobre la autoeficácia (pp. 178-186). Castelló de la Plana: Publicacions de la Universitat Jaume I, D.L.

Navarro, L. P. (2007). Autoeficacia del professor universitário: Eficacia percebida e practica docente. Madrid: Narcea, S. A. de ediciones.

Pajares, F., \& Olaz, F. (2008). Teoria social cognitiva e auto-eficácia: uma visão geral. In A. Bandura, R. G. Azzi, \& S. Polydoro (Eds.), Teoria social cognitiva: conceitos básicos (pp. 97-113). Porto Alegre: Artmed.

Schwarzer, R., \& Schmitz, G. S. (2004). Perceived self-efficacy as a resource fator in teachers. In M. Salanova, R. Grau, I. M. Martínez, E. Cifre, S. Lorens, \& M. Garcia-Renedo (Eds.), Nuevos horizontes em la investigación sobre la autoeficácia (pp. 229-236). Castelló de la Plana: Publicacions de la Universitat Jaume I, D.L.

Sharma, U., Loreman, T., \& Forlin, C. (2012). Measuring teacher efficacy to implement inclusive practices. Journal of Research in Special Educational Needs, 12(1), 12-21. DOI: https://doi. org/10.1111/j.1471-3802.2011.01200.x

Soares, M. B., \& Machado, L. B. (2014). Violência contra o professor nas representaçóes sociais de docentes. Perspectiva, 32(1), 333-354. DOI: https://doi.org/10.5007/2175-795X.2014v32n1p333

Souza, A. C., Alexandre, N. M. C., \& Guirardello, E. B. (2017). Propriedades psicométricas na avaliação de instrumentos: avaliação da confiabilidade e da validade. Epidemiologia e Serviços de Saúde, 26(3), 649-659. DOI: http://dx.doi.org/10.5123/s1679-49742017000300022

Tabachnick, B. G., \& Fidell, L. S. Using multivariate statistics. Boston: Pearson, 2013.

Tschannen-Moran, M., \& Woolfolk Hoy, A. (2001). Teacher efficacy: Capturing an elusive construct. Teaching and Teacher Education, 17(7), 783-805. DOI: https://doi.org/10.1016/S0742051X(01)00036-1

Vitaliano, C. R., \& Valente, S. M. P. A formação de professores reflexivos como condição necessária para inclusão de alunos com necessidades educacionais especiais. In C. R. Vitaliano (Ed.), Formação de professores para inclusão de alunos com necessidades educacionais especiais (pp. 31-48). Londrina: EDUEL, 2010.

Woolfolk, A. E., \& Hoy, W. K. (1990). Prospective Teachers' Sense of Efficacy and Beliefs About Control. Journal of Educational Psychology, 82(1), 81-91. DOI: https://doi.org/10.1037/0022-0663.82.1.81

Woolfolk Hoy, A., \& Burke-Spero, R. (2005). Changes in teacher efficacy during the early years of teaching: A comparison of four measures. Teaching and Teacher Education, 21, 343-356. DOI: https://doi.org/10.1016/j.tate.2005.01.007-

Submetido em 31/05/2019

Reformulado em 06/10/2019

Aceito em 03/11/2019 
MARTINS, B.A. \& CHACON, M.C.M. 